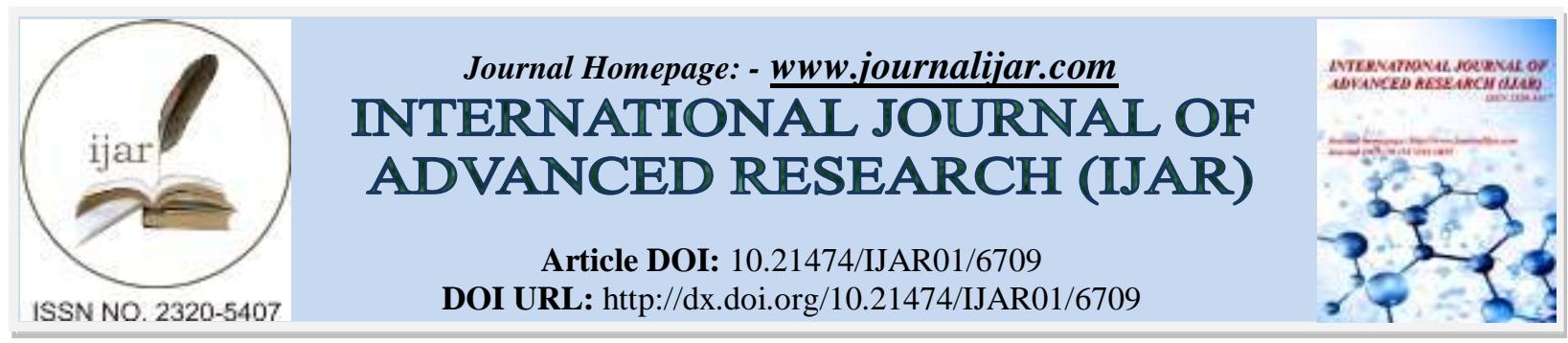

RESEARCH ARTICLE

\title{
EXPERIMENTAL INVESTIGATION OF THE MECHANICAL AND PHYSICAL PROPERTIES OF CRUMB RUBBER CONCRETE TREATED BY WATER SOAKING METHOD.
}

\author{
Asst. Prof. Dr. Nagham Tariq Hamad Al-Shafii, Lect. Dr. Raid R. A. Almuhanna and Humam Abd Al-Razaq \\ Noaf. \\ Al-mustansiriayah university- highways and transportation engineering department-baghdad-iraq. And University of \\ Kerbala.
}

\section{Manuscript Info}

\section{Manuscript History}

Received: 09 January 2018

Final Accepted: 11 February 2018

Published: March 2018

Keywords:-

rubber, water soaking, treated rubber.

\begin{abstract}
The colossal utilization of materials expands the waste which causes collection in landfill, as well the huge using on structure materials with minimal cost, light weight, high insulation properties with acceptable strength resulted searching for new ecologically friendly materials. Expanded utilization of waste materials, for example crumb rubber etc. one of the different issues which humankind confront as it goes to the 21 st century is the issue of waste tire elimination administration. Since materials such as rubber don't break down effortlessly, elimination of rubber waste is an excruciating environmental trouble. This paper deals with the study of mechanical and physical properties of the concrete mixture containing rubber replace by sand and the mixture containing rubber. Three ratios for rubber are taken 5, 10 and 15 then choose the best proportion of them. Crumb rubber was treated by water soaking method, this method considered economical and effective.
\end{abstract}

Copy Right, IJAR, 2018,. All rights reserved.

\section{Introduction:-}

Throughout the years there has found attention for utilization of reused waste rubbers in expressway development. Filled concrete by waste rubber, Portland cement as rubberized material replace with a part of aggregate by CR, speaks to an alternative of utilizing reused waste rubber. It is discovered that concrete-rubber has high durability. Be that as it may, its strength reductions fundamentally as the CR content increments. This restrains its implementation $\mathrm{CRC}$ only in secondary construction parts. In this segment, diverse characteristics of crumb rubber concrete (CRC) are examined comprehensively. In consideration of the accessible study information, the function of CR particles in matrix of concrete is critically criticized. In addition, group's classifications of reused CR and their impacts on properties of concrete are expounded. The decreases in concrete compressive strength produced with CRC its utilization in many applications, (Bayomy, 1999). Function property that evaluates the decreases in strength for CRC blends were created that could be valuable for mix design intent. CRC blends might be appropriate for purposes of nonstructural, for example, building veneers, lightweight walls of concrete and architectonic units. They could likewise be utilized as bases of cement. Fire risks are of real concern and should be completely explored before suggestions for useful execution are drawn, (Khatib and Bayomy, 1999). The decrease in compressive quality of concrete produced with CR constrains its utilization in many applications, (Khatib and Bayomy, 1999, Khaloo et al., 2008, Ling, 2009, Bewick, 2010). In any case, CRC has perhaps some alluring qualities, for example, lower density, (Khatib and Bayomy, 1999, Khaloo et al., 2008) and higher strength and elasticity, (Topcu, 1997, Zheng et al., 2008). 
Water soaking is a method used to treat rubber, which is inexpensive and makes the mixture more homogeneous, the particles of rubber are distributed regularly. This strategy leads to a best bond between the rubber particles and the concrete mixture There are a few difficulties, for example, absence of homogeneity and lessening of strength, When adding rubber to pavement blend, (John and Kardos, 2011).

Procedure of water soaked method to introducing rubber into concrete mix

Step 1: Place the rubber in the water container for 24 hours.

Step 2 Remove the rubber from the water container and put in air to dry for 24 hours.

Step 3: after that can be used the rubber instead of sand in concrete mix.

\section{2-Materials and Methodology}

There is no doubt that the best alternative to minimize the impact on the environment from the consumption of raw materials is through the reuse of waste materials. Crumb rubber was added to concrete as fine aggregate was investigated and compared with ordinary concrete. Ordinary concrete contains $45 \%$ w/c ratio. Crumb rubber treated by water soaking method as shown previously in chapter three resulted in increase the compressive strength of concrete mix.

\subsection{Material Used}

In this paper used normal portland cement made in Tasuloja factory in Iraq. The physical properties of cement were tested by National Center for Laboratories and Construction Research (NCCLR), and conformity with the Ministry of Planning / Central Agency for Standardization and Quality Control Manual 198/1990,(IQS, 1984c) as shown in Table (2.1). Sand was used from the Al-Ekhaider quarry the physical properties of sand shown in Table (2.2). coarse aggregates were used from the Al-Nabai area hysical properties of coarse aggregate shown in Table (2.3). The crumb rubber that was cut in the Babylon Tires factory

Table (2.1) Physical Properties of cement

\begin{tabular}{|l|l|l|}
\hline Physical properties & Test result & $\begin{array}{l}\text { L.I.S No.5/1984, } \\
\text { (IQS, 1984c). }\end{array}$ \\
\hline Fineness (m2/kg) & 370 & 230 \\
\hline Autoclave exp. & 0.32 & $0.8 \%$ \\
\hline $\begin{array}{l}\text { Compressive strength (MPa) } \\
\text { 3-days age }\end{array}$ & 29.5 & 15.0 \\
\hline $\begin{array}{l}\text { Compressive strength (MPa) } \\
\text { 7-days age }\end{array}$ & 35 & 23.0 \\
\hline Time of setting Initial (min.) & 35 & 45 \\
\hline Time of setting final (hour) & 5.25 & 10 Max. \\
\hline
\end{tabular}

Table (2.2) Physical Properties of Fine Aggregate

\begin{tabular}{|l|l|l|}
\hline Physical properties & Test result & $\begin{array}{l}\text { L.I.S, (IQS, 1984b) specification } \\
\text { No.45/1984 }\end{array}$ \\
\hline Specific gravity & 2.60 & - \\
\hline Sulfate content & $0.11 \%$ & $0.5 \%(\max )$ \\
\hline Absorption & $0.75 \%$ & - \\
\hline
\end{tabular}

Table (2.3) Physical Properties of Coarse Aggregate

\begin{tabular}{|l|l|l|}
\hline Physical properties & Test results & $\begin{array}{l}\text { L.I.S No.45/1984, } \\
\text { (IQS, 1984a) }\end{array}$ \\
\hline Specific gravity & 2.60 & - \\
\hline Sulfate content & $0.06 \%$ & $0.1 \%(\max )$ \\
\hline Absorption & $0.75 \%$ & - \\
\hline
\end{tabular}




\section{Results and Discussions:-}

\subsection{Effect of Density}

The density was calculated by measure the weight of the sample and divides by volume $(\mathrm{Kg} / \mathrm{m} 3)$. Plate (3.1) shown balance sensitive to take dry weight and surface-dry mass after immersion weight. according to (ASTM C642-97). Average of three specimen's results was determined from cubes $(100 * 100 * 100) \mathrm{mm}$ were taken to determined wet density and dry density. The concrete cubes were tested at age of (3, 7 and 28). Wet and bulk densities were measured, as shown in Figures (3.2) and (3.3). The density of concrete decreases when rise the percentage of CR. It has been shown that rising the percentage of CR leads to a decrease in the density of the mixture. Air content in the mix increases with raising the proportion of $C R$ lead to reduction the mix density.

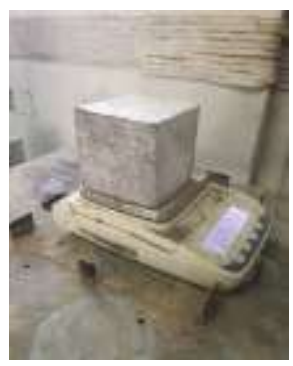

Plate (3.1) Balance Sensitive to Take Dry Weight and Surface-Dry Mass after Immersion Weight.

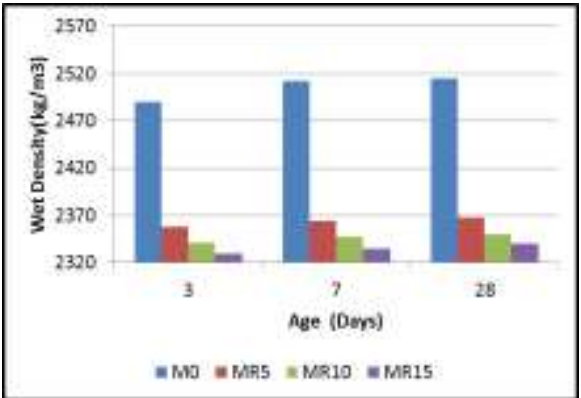

Figure (3.2): Wet Density for Varies Percent of Rubber

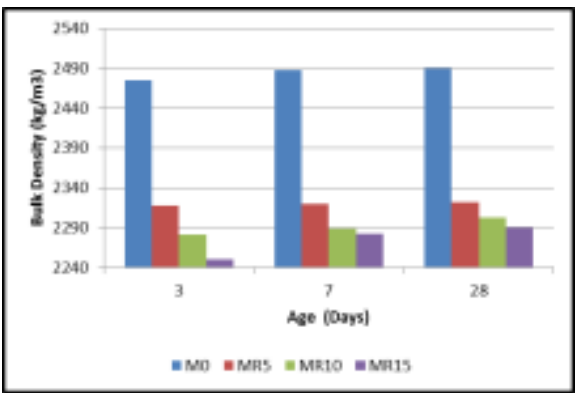

Figure (3.3): Bulk Density for Varies Percent of Rubber

\subsection{Effect of Water Absorption}

Three cubes with dimension $(100 * 100 * 100) \mathrm{mm}$ were tested for each mix at 28 days of curing to determine the Absorption of water according to, (ASTM, 1997). After 28-day concrete samples was dried in an electric oven with a temperature of $100-105^{\circ} \mathrm{C}$ for 24 hours. Dry samples were weighed by an electronic balance and the dry weight of the sample was (W1). The samples were then immediately immersed in water at $15-20^{\circ} \mathrm{C}$ for 24 hours (W2) and the percentage of absorption was calculated as follows:

Water Absorption \% $=((\mathrm{W} 2-\mathrm{W} 1) / \mathrm{W} 1) \times 100$

Eq (2.1) 
The results show that with increased rubber ratio leads to increased water absorption. Figure (3.4) shows the effect of different ratios of rubber to aggregate on the water absorption of mixture.

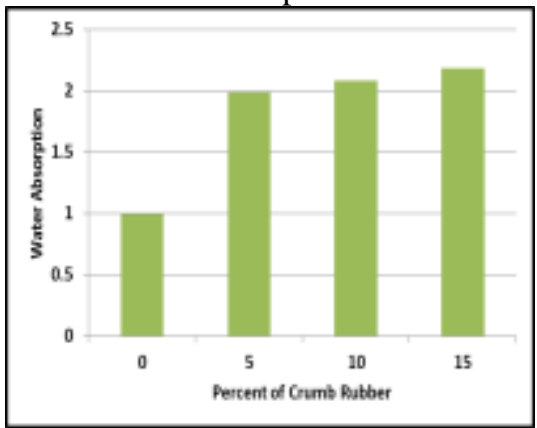

Figure (3.4): Absorption Ratio for Varies Percent of Rubber

\subsection{Effect of Compressive Strength}

An average compressive strength $\left(f^{\prime} \mathrm{c}\right)$ average of three specimen's results was determined from $(100 * 100 * 100) \mathrm{mm}$ cubes axially stressed at rate of 20MPa as shown in Plat (3.5) according to ASTM C39/86, (ASTM, 2006a).the concrete cubes were tested at age of (3,7 and 28) using digital compression testing machine of $2000 \mathrm{KN}$ capacity. The concrete age and its effect on compressive strength for varies percent of rubber as shown in Figure (3.6). Through the results show raised CR content lead to reduction compression strength. It is quite obvious from that the compressive strength decreased with the increasing in CR content.

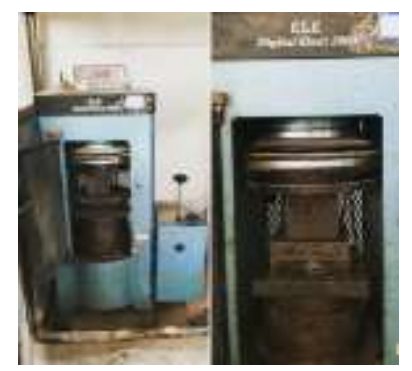

Plate (3.5) Digital Elect2000 for Measure Compressive Strength

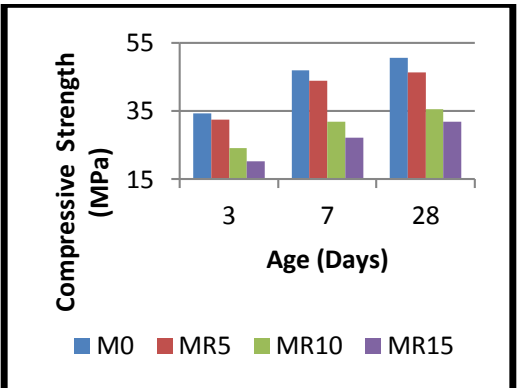

Figure (3.6): The Concrete Growth and Its Effect on Compressive Strength for Varies Percent of Rubber

\subsection{Flexural Strength Test}

The flexural strength was performed on $(100 * 100 * 500) \mathrm{mm}$ prisms under two point loading as shown in Plate (3.7) according to ASTM C78-84(ASTM, 2006b) using flexural testing machine of $600 \mathrm{KN}$ capacity. The average of three prisms was taken at age 28 days for each mix type. It is clearly noticed that the two percent's of rubber ( $10 \%$ and 15\%) gave close values of flexural strength (MR10 was more than MR15 by $6.2 \%$ ). The Effect of flexural strength when add CR at 28 day curing time shown in Figure (3.8). The modulus of rupture was calculated as following:

$\mathrm{R}=\mathrm{PL} / \mathrm{bh} 2$

$\mathrm{Eq}(3.1)$

where 
$\mathrm{R}=$ modulus of rupture $(\mathrm{MPa})$

$\mathrm{P}=$ maximum applied load $(\mathrm{N})$

$\mathrm{b}=$ width of prism $(\mathrm{mm})$

$\mathrm{h}=$ depth of prism $(\mathrm{mm})$

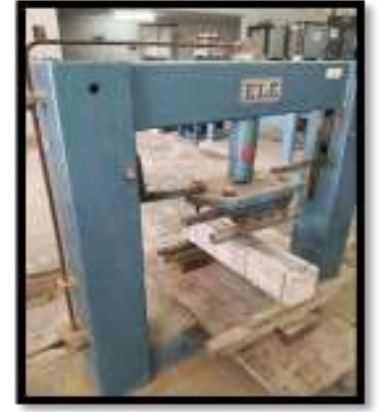

Plate (3.7) Device for Testing Flexural Strength

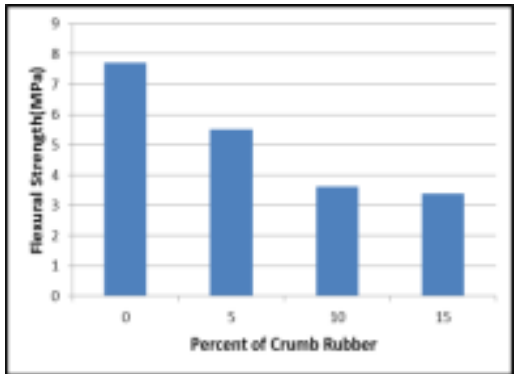

Figure (3.8): Flexural Strength for Varies Percent of Rubber

3.5 Splitting Tensile Strength

A cylinders of $(100 * 200) \mathrm{mm}$ were prepared according to ASTM C496/C496M-04, (ASTM, 2006c)specification. Plate (3.9) shown Digital Elect2000 for Measure Splitting Tensile Strength. Splitting Tensile Strength Cylinders were tested at 28 days and the average of three specimen's results was adapted for each mix type. The splitting tensile strength values are shown in Figure (3.10). The splitting tensile strength of MR10 is less than MR5 by (10.87\%) more than MR15 by (3.05\%) at 28 days curing in water. Increasing the volume of the rubber reduces splitting tensile strength. Splitting tensile strength depends on several factors such as the bond surface and strength of the cement dough, the bond between the cement paste and the rubber is weak for this less splitting tensile strength. The splitting tensile strength values were calculated by the following expression:

$\mathrm{T}=2 \mathrm{P} / \pi \mathrm{dL}$

$\mathrm{Eq}(3.3)$

where

$\mathrm{T}=$ splitting tensile strength $(\mathrm{MPa})$

$\mathrm{p}=$ maximum applied load $(\mathrm{N})$

$\mathrm{d}=$ Diameter of cylinder $(\mathrm{mm})$

$\mathrm{L}=$ Length of cylinder $(\mathrm{mm})$

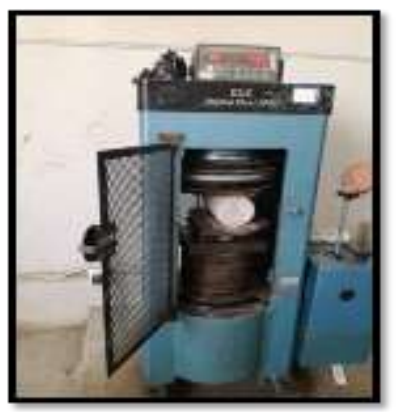

Plate (3.9) Digital Elect2000 for Measure Splitting Tensile Strength 
Splitting Tensile Strength

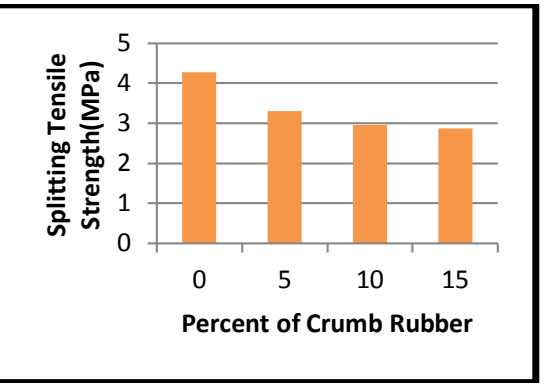

Figure (3.10): Splitting Tensile Strength for Varies Percent of Rubber

\section{Conclution:-}

The compressive strength of the blends reduce with the rise of CR content for all trials and curing periods (3, 7 and 28 days) as shown in Figure(3.4). The increases in CR content lead to reduced the dry density because the specific gravity of CR is a little as shown in Figure (3.1) and (3.2). Water absorption of CR mixtures rises with increase CR content as shown in Figure (3.3). Considerable reduction in flexural strength was recorded in mixtures containing rubber particles as shown in Figur(3.5). Recycled CR reduces the splitting tensile strengths of concrete as shown in Figure (3.6). Basing on the results can be determined that optimum at 10\% of CR/aggregate ratio. Depending on these results, rubber can be used as an alternative to sand in concrete mix in construction buildings. The decrease in strength depended on the economically viable, environmentally effective.

- $\quad$ IQS 1984. "test of cement properties,".No.5/1984 Iraqi Reference Guide indicative (198) and the Ministry of Planning / Central Agency for Standardization and Quality Control Manual198/1990.

- IQS 1984. , No. 45/1984"Aggregate from Natural Sources for Concrete," Central Agency for Standardization and Quality Control, Planning Council, Baghdad, Iraq, translated from Arabic edition. .

- $\quad$ ASTM 1997. C642-97"Standard Test Method for Density, Absorption, and Voids in Hardened Concrete, March," ASTM International.

- $\quad$ ASTM 2006. C39/C39M-05"Standard Test Method for Compressive Strength of Cylindrical Concrete Specimens," ASTM International

- $\quad$ ASTM 2006b. C78-84"Standard Test Method for Flexural Strength of Concrete (Using Simple Beam with Third-Point Loading)," ASTM International

- $\quad$ ASTM 2006c. C496/C496M-04"Standard Test Method for Splitting Tensile Strength of Cylindrical Concrete Specimens," ASTM International.

- $\quad$ BAYOMY, K. 1999. "Application of Recycled Rubber in Concrete Pavements".

- $\quad$ KHATIB, Z. K. \& BAYOMY, F. M. 1999. "Rubberized Portland cement concrete,". Journal of materials in civil engineering, vol. 11, p. 206-213.

- $\quad$ BEWICK, B., DRIVE, B, AIR, T, BASE, F, SALIM, HA \& SAUCIER, 2010. "Crumb Rubber-Concrete Panels Under Blast Loads,”. Air Force Research Laboratory, Materials and Manufacturing Directorate, p. 1-14.

- $\quad$ KHALOO, A., D., M \& RAHMATABADI, P. 2008. "Mechanical properties of concrete containing a high volume of tire-rubber particles,". Waste Management,, vol. 28, p. 2472-82.

- TOPCU, I. 1997. "Assessment of the brittleness index of rubberized concretes,". Cement and Concrete Research, vol.27, p. 177-183.

- $\quad$ ZHENG, L., , H. X. \& AND YUAN, Y. 2008. "Strength, Modulus of Elasticity, and Brittleness Index of Rubberized Concrete,". Journal of Materials in Civil Engineering,, vol.20, p. 692-699.

- $\quad$ LING, T.-C., NOR, HM, HAININ, MR \& CHIK, AA 2009. "Laboratory performance of crumb rubber concrete block pavement,". International Journal of Pavement Engineering, vol. 10, no. 5, p. 361-374.

- JOHN, A. \& KARDOS, A. 2011. "Beneficial use of crumb rubber in concrete mixtures,". University of Colorado, p. 1-209. 